\title{
Can "I" prevent you from entering my mind?
}

\author{
Marc Champagne
}

Published online: 27 January 2011

(C) Springer Science+Business Media B.V. 2011

\begin{abstract}
Shaun Gallagher has actively looked into the possibility that psychopathologies involving "thought insertion" might supply a counterexample to the Cartesian principle according to which one can always recognize one's own thoughts as one's own. Animated by a general distrust of a priori demonstrations, Gallagher is convinced that pitting clinical cases against philosophical arguments is a worthwhile endeavor. There is no doubt that, if true, a falsification of the immunity to error through misidentification would entail drastic revisions in how we conceive the boundary between self and other. However, I argue that (1) the idea of unearthing an exception to the Cartesian thesis is, on further reflection, not a realistic prospect and that (2) this casts doubt on the attempt to conjoin first-person phenomenology and third-person cognitive science in the service of philosophical debates.
\end{abstract}

Keywords Self-recognition · Recognition of another P Pychosis · Thought insertion · First-person authority $\cdot$ A priori argumentation

Hurdles between egos - unlike those between cells, which are surrounded by semipermeable membranes, allowing the passage of certain chemicals and thereby certain information - are insurmountable.

Thomas A. Sebeok (Global Semiotics, 2001)

\section{Introduction}

Shaun Gallagher has actively looked into the possibility that schizophrenic psychopathologies involving "thought insertion" might supply a counterexample to

M. Champagne $(\triangle)$

Department of Philosophy, York University, 4700 Keele Street, Toronto, ON, Canada M3J 1P3

e-mail: gnosiology@hotmail.com 
the supposedly universal principle according to which one can always recognize the contents of one's consciousness as one's own. John Campbell fleshes out the philosophical relevance of such clinical disorders as follows:

In making a judgement like, "I see a comet," there are not two steps, finding out who is seeing the thing and finding out what it is that is being seen, so that you could go wrong at either step. The only place to go wrong is in your description of what is being seen. [...] A patient who supposes that thoughts have been inserted into his mind by someone else is right about which thoughts they are, but wrong about whose thoughts they are. So thought insertion seems to be a counterexample to the thesis that present-tense introspectively based reports of psychological state cannot involve errors of identification. (Campbell 1999b, pp. 609-610; emphasis added)

Descartes, you will recall, fell back on the immediacy of his own thinking self to dissipate the (remote, but nevertheless conceivable) possibility of wide-scale deception. One's privileged access to one's own mind, he held, supplies one with an internal preserve forever beyond the reach of any cunning agency who would perchance attempt to beguile one. ${ }^{1}$ Hence, while I may be wrong about a great many things, I can never be wrong about the fact that even when contemplating a falsehood it is $I$ who is thinking-thereby alleviating my fallible epistemological predicament as a finite creature on at least one front. Following Sydney Shoemaker (1968, p. 556), we can label this the "immunity to error through misidentification" principle. ${ }^{2}$ For sundry reasons ranging from the sophisticated to the mundane, philosophy and folk psychology alike have found solace in the idea that, come what may, one's thoughts are always transparently one's own. But, if Campbell is correct, then empirical studies of schizophrenia challenge this traditional construal of the self. Instead of tagging a private "I think that..." before every mental content, some schizophrenic patients are seemingly coerced by something beyond their control to add the prefix "Someone else thinks that..." in a certain (for our purposes, undefined) subset of experiences.

Although a healthy level of prudence prevents him from taking a definitive stance on the issue, Shaun Gallagher is convinced that grappling with this remarkable possibility is a worthwhile endeavor:

It may be argued whether or not Campbell is correct in his claim that this [misidentification by a schizophrenic patient of the source of her thoughts] is a counterexample to the immunity principle, but the implications of his analysis are quite productive. [...] If we can identify which mechanisms fail at the cognitive or neurological level when the schizophrenic patient suffers from thought insertion, then we also have a good indication of the mechanisms

\footnotetext{
${ }^{1}$ In the Meditations, this idea is gleaned partly by way of introspection, but is buttressed by ample rational argumentation (see Frankfurt 1970).

2 The issue of how (i.e., when and to what) to apply the first-person pronoun is of obvious relevance to the philosophy of language - as witnessed by L. Wittgenstein's influential remarks on the matter (1958, pp. 66-67), but it bears on the study of the mind as well. In fact, some theorists have argued that the very ability to conceive of oneself as oneself "is signaled by the linguistic ability to attribute (as well as to make) first-person reference to oneself” (Baker 2000, p. 68).
} 
responsible for (or at least involved in) the normal immunity to error found in self-reference, and the immediate sense of self. This insight moves us from the conceptual and often abstract arguments of philosophy to the more empirical inquiries of neuropsychology and neurophysiology. (2000a, p. 16)

The transition from the a priori to the a posteriori alluded to in this passage is assumed to be a salutary one. Gallagher (2007a, p. 295) quotes disapprovingly Gilbert Ryle's statement that "One will never say that so and so is a better philosopher than so and so because so and so knows facts of which the other is ignorant" (in Merleau-Ponty and Ryle [1960] 1992, p. 68). A received naturalism indeed makes Ryle's stance sound hopelessly isolationist. The widespread holism which helped usher in this naturalist turn has it that, under the right conditions, contingent observations can compel us to modify (and even abandon) truths we hitherto took to be analytically secure.

Yet, the holistic take on knowledge which contributed to undermining this divide also tells us that certain "core" items can be prized so much that they can be entrenched even in the face of mounting counter-evidence. Whether or not it gets dislodged by aberrant cases, Descartes' influential philosophical claim vis-à-vis the infallibility of reflexive first-person apprehension certainly qualifies as such a tenacious tenet. So, in spite of Gallagher's calculated agnosticism, there has to be some genuine prospect of falsifying the aforementioned immunity principle for the claim of "productivity" to go through as more than idle comparison work. If that remote possibility can be shown to be outright impossible, then one can rightly ask what the point of the endeavor is.

My aim in this paper, then, is twofold. On the one hand, I want to try and show that the idea of unearthing a vivid exception to the self's self-referential immunity is, on further reflection, not a realistic prospect. On the other hand, I want to use Gallagher's multidisciplinary investigation of thought insertion as a springboard to explore some methodological issues that are sometimes papered over in the interest of presenting a united front. Dividing my discussion into four parts, I will start with substantive explanations of schizophrenia and progressively work my way into more general methodological considerations.

I will begin by reviewing the standard account of thought insertion, which turns on the idea of a comparison between express intents and bodily actions across time ("Sense of agency and bodily action"). I will then examine the rival (Husserlian) model defended by Gallagher and will critically probe his claim that it presents a better, more plausible, alternative ("A rival model of schizophrenia"). This will lead me to address important questions pertaining to the epistemological status of first-person reports ("The status of first-person reports"). Finally, I will return to the essay's title query and ask whether the foregoing considerations truly call into question the reasoning that underpins the immunity to error through misidentification principle ("Coming full circle"). Coupled with the fact that the promise of a counterexample to this Cartesian thesis ultimately goes unmet, I believe the sundry tensions I will lay bare cast serious doubt on the overall viability of Gallagher's attempt to conjoin first-person phenomenology and third-person cognitive science in the service of philosophical debates. I will conclude by suggesting that this might stem from a hasty naturalist engagement with problems (and solutions) which have a decidedly a priori status. 
It is important to underscore the limited scope of that concern. The claim is not that the admixture of first-person phenomenology and third-person cognitive science advocated by Gallagher and others fails to work across the board. However, it is one thing to argue that controlled first-person reports are a factor that should be taken into consideration in the design of experimental set-ups-that "no-brainer" (Gallagher and Brøsted Sørensen 2006, p. 130) is uncontroversial enough-and quite another to suggest that this approach has the power to overturn centuries-old philosophic tenets supported by monotonic argumentative means. That obviously does not foreclose a shared future for phenomenology and the cognitive sciences, but adopting a more modest program entails a corresponding change in the selection of problematics deemed germane and/or feasible. In a spirit of constructive sobriety, I here focus on a telling instance where this has not been the case.

\section{Sense of agency and bodily action}

Following Irwin Feinberg (1978) and Christopher Frith (1992), it is customary to explain the phenomenon of "thought insertion" by way of an analogy with pathologies of motor control, specifically those that pertain to visuo-motor coordination (see Campbell 1999b, pp. 611-614). The analogy is cashed-out by Gallagher and others as follows: if, under suitable circumstances, a limb or apparatus once deemed to be fully under a person's agentive control can be made to appear completely foreign, then analogous circumstances might also account for cases where persons insist the thoughts they are having are not "really" theirs and have been placed in their stream of consciousness by another person (Bortolotti and Broome 2009, pp. 214-215).

As one seeks to grasp an object, one constantly has to adjust one's movements in the light of proprioceptive feedback. This self-monitoring would seem to be tied intrinsically to one's body. However, experiments and phenomenological descriptions strongly suggest that-modulo a certain period of adaptation-the entire process can just as easily be transposed on a material surrogate designed to extend one's motor commands. That is, the feedback loop can quite literally encompass a foreign body. Gallagher (2006, p. 197) cites the case of NASA engineers working with sophisticated robotic arms who, deprived of any direct view of their own body by "virtual reality" goggles, eventually came to project a strong sense of embodiment onto the mechanical apparatus (which was situated elsewhere): "This was manifest when one of us thought that he had better be careful for if he dropped a wrench it would land on his leg" (cited in Cole et al. 2000, p. 167). These reports suggest that the commonsensical delineation marking out the domain of selfhood can be augmented in cases where one's agentive dominion over an external object answers to roughly the same parameters as self-initiated bodily motions. ${ }^{3}$

\footnotetext{
${ }_{3}^{3}$ Interestingly, this plasticity was noticed by Merleau-Ponty in the course of his own phenomenological investigations: "The blind man's stick has ceased to be an object for him, and is no longer perceived for itself; its point has become an area of sensitivity, extending the scope and active radius of touch, and providing a parallel to sight. In the exploration of things, the length of the stick does not enter expressly as a middle term: the blind man is rather aware of it through the position of objects than of the position of objects through it" ([1945] 1974, p. 143).
} 
Since the employment of more "visceral" (proprioceptive) pathways presumably unfolds at a wholly subpersonal level, it is doubtful that an engineer involved in complex robotic maneuvers could ever truly dissipate her feeling of exercising an intimate control over the machine by rehearsing declarative statements to the effect that this sense of direct mastery is in point of fact highly mediated. As Husserl would say, "his depriving them of acceptance, does not signify their disappearance from his field of experience" ([1931] 1999, p. 20). Likewise, telling a patient afflicted by thought insertion that the whole affair is illusory does little to dissipate the overwhelming phenomenological feeling of intrusion by some other party. We can therefore begin to see the attractiveness of exploiting the example of visuo-motor coordination in order to wedge an explanatory hypothesis in what otherwise appear to be inscrutable psychological disorders.

The case of the "embodied" robotic arms is subject to crucial diachronic constraints: temporal immediacy is required for the sense of spatial immediacy in one's actions to emerge. If too long a delay is introduced between the bodily commands of the engineer and the movements of the machine, the naturalness of the feedback loop begins to break down. Indeed, experiments "which used a delay between the subject's movement and the resultant tactile stimulation, demonstrated that the perception of a tactile stimulus is proportional to the sensory discrepancy produced by the comparison between the predicted and actual sensory feedback from the movement" (Blakemore 2000, p. 198). ${ }^{4}$ In the example previously cited, the NASA operator was already making provisions for the next action when the robot was executing a previous command. Similarly, in everyday experience, one does not wait to see what will happen when one has initiated a familiar motor command. Instead, one anticipates that the action will occur in an independent manner that requires no further sanction (Haggard and Clark 2003) _ just as one need not concentrate on external happenings for efficient causality to do its work. As Heidegger would say, owing to the body's primitive involvement with the world, the various meanings we traffic in are always already "ahead" of themselves. However, this smooth sense of obviousness - which is truly remarkable in that it underwrites an almost "animistic" analogy between agency's orderliness and worldly occurrences - is not necessarily abiding, and is liable to collapse under specific circumstances. Again, to echo a quintessentially Heideggerian theme, this breakdown of the expected cause-and-effect sequence thereby reveals an artificial implement anew for what it really is, or alternatively gives one the sense that one's limbs are disembodied material objects (Gallagher 2004a; Slatman 2009). ${ }^{5}$

\footnotetext{
${ }^{4}$ Gallagher (2006, p. 199) reports on experiments conducted by Nielsen (1963) and Franck et al. (2001) that show how discrepancies in feedback which last beyond $150 \mathrm{~ms}$ begin to dissipate the phenomenological feel of the control as im-mediate. One virtually unnoticed implication of such studies is that, if the sense of agency is inversely proportionate to the delay, then the lower limit of such a temporal gradation (which marks no discrepancy) would have to entail an absolute agentive involvement in an hic et nunc event. If so, then this calls into question the centrality of an outflowing-inflowing dynamic, insofar as an "instantaneous feedback" bereft of any sequentiality is no feedback at all. See Champagne (forthcoming) for the methodological consequences of this important (but otherwise unexplored) idea.

${ }^{5}$ That is not to say that something so disclosed in its artificiality suddenly falls outside the purview of one's volitional control; after all, a NASA engineer would remain very much in charge of a robotic surrogate even if her commands were conveyed under exaggerated temporal parameters (say, by regular mail).
} 
According to Blakemore, "[o]ur sensory systems are constantly bombarded by a multitude of sensory stimuli, from which we must extract the few stimuli which correspond to important changes within the environment. One class of stimuli that are in most circumstances of little biological importance are those that arise as a necessary consequence of our own motor actions" (2000, p. 185). As we have just seen, the close sequential succession of command and execution means that, in most situations, the feedback one gets from moving one's own body effectively effaces itself. Blakemore's account corroborates this and adds a plausible evolutionary rationale for why it is so: since diverting limited cognitive resources towards processing and categorizing the information accompanying bodily actions would adversely affect our ability to fruitfully deal with our environment, considerations of economy inscribed in our very constitution as animals require us to attenuate such proprioceptive feedback as needlessly wasteful excess (although that information is presumably always there in latent form, as a pre-reflective background of experience).

However, in cases where one's intentions do go astray, such as when delays and distortions are (experimentally or pathologically) introduced, this "feeling of doing" (Bayne and Levy 2006) springs to the phenomenological foreground as a salient item calling for cognitive attention and this, for the very same Darwinian reasons which warrant its disregard in normal contexts. These varying shades of salience, in turn, help organisms distinguish what is and what is not within their purview. "As the error from this comparison [between predicted and actual sensory feedback] increases so does the likelihood that the sensation is externally produced" (Blakemore 2000, p. 187, emphasis added; see also Johnson 1988; Farrer and Frith 2002). One might conceivably adjust oneself to this over time. But, in the short-term at least, what is lost in stretching (or severing) the feedback loop is the feeling that the vehicle for action was "within" the sphere of one's selfhood. ${ }^{6}$

\section{A rival model of schizophrenia}

The explanations of thought insertion that exploit an analogy with motor control are premised on a generic construal that allows one to (1) initiate an action (perhaps in light of an external prompting) and (2) subsequently verify whether that pre-motor command has been properly executed - the weak normative term "properly" here meaning (2a) in conformity with the original intent and (2b) in a timely manner. To the extent one endorses this way of thinking, some means of preserving the substantive content of one's intent(s) across time is needed for the whole dynamic to

\footnotetext{
${ }^{6}$ It has long been recognized that schizophrenia can lead to social dysfunctions (Lysaker et al. 2005). If what has just been said is correct, then suffering from a severe dislocation in what does and does not appear under one's willful control also robs one of a pivotal epistemological compass (Waldenfels 2004). In conformity with the account given by Blakemore (2000), fecund dealings with one's environment would seem to require that one's first-person phenomenology include relatively tranquil zones free of the sense of surprise, so that truly novel events may better capture one's attention and trigger further inquiry (Schwartz et al. 2005, p. 102). By contrast, the mind of a schizophrenic is ostensibly cluttered with a needlessly high degree of foreignness that hinders (or even precludes) the attainment of an objective worldview (Gallagher 2009a, p. 256).
} 
take place. If I want to move my foot to the left, it is not sufficient that shortly thereafter, I move my foot; for the end-result to conform to my intent and be regarded as my own, that foot must have moved to the left as originally envisaged. We may thus surmise that some sort of copy is made whenever a motor command is sent out, in order to capture with a high enough degree of fidelity these pre-action neural processes. Moreover, it seems reasonable to posit some kind of subpersonal self-monitoring mechanism whose task it is to use that efferent copy in order to compare outflowing pre-motor intents with actual behavioral results.

Not surprisingly, most current theories follow something like this line of reasoning - the prime example here being the influential work of Frith (1992). Gallagher, however, has amply criticized the resultant account, since, in his view, "the comparator/efferent copy model makes little phenomenological sense and is in some respects redundant or extraneous" (2000b, p. 230; see also his 2004c, pp. 1115). In its stead, he urges a model based on Husserl's reflections ([1893-1917] 1991) which would describe the same data by appealing to a breakdown in "protention"that is, a failure to have the upcoming moment as an intentional object (Gallagher 2006, pp. 189-196; Gallagher 1998; Lethin 2008). Consider, for example, sentence completion, a handy device used by Gallagher (2006, pp. 194-195) to illustrate the workings of protention in the stream of consciousness. As one reads the syntagmatic concatenation "George quickly swallowed...," one is diachronically building up expectations which constrain the synchronic paradigm of possible lexical units most likely to appear next, before they appear. The process lends itself well to a (Saussurean) linguistic characterization, but it is meant to capture a ubiquitous phenomenological feature: "Every subjective process has a process 'horizon,' which changes with the alteration of the nexus of consciousness to which the process belongs and with the alteration of the process itself from phase to phase of its flow [...] a continuous protention, which, with each phase of the perception, has a new sense" (Husserl [1931] 1999, p. 44). Gallagher uses this Husserlian framework to account for thought insertion by arguing that "[w]ithout protention, thought continues, but it appears already made, not generated by me, appearing suddenly, already formulated as it enters into retention" (Gallagher 2006, p. 195).

However, the description given by Gallagher lists a host of features, not all of which are called for by the Husserlian model. Indeed, if we suppose that failure (or privation $)^{7}$ of protention is a central causal factor, the fact that a thought "appears suddenly" as "already formulated" does not necessarily mean that it will be felt as "not generated by me" - it might just as easily yield, say, a delusional sense of omnipotence. Now, Gallagher rightly notes that "a lack of a sense of self-agency does not add up to an attribution of action to others" (2007b, p. 43). As such, the picture needs to be made more complete by allowing that "[i]n metarepresentation the [schizophrenic] patient may start to ascribe the thought to some particular force or individual and report that it has been inserted" (Gallagher 2006, p. 196). But, since that second-order ascription is what allows the first-order lack of anticipation to be glossed as an intervention by some other party, then in the end, what really does the explaining of schizophrenic thought insertion is metarepresentation, not

\footnotetext{
${ }^{7}$ This distinction between impairment and outright lack, though plainly crucial for diagnosis and treatment, is rarely made.
} 
lack of protention. And that second-order ascription-unfolding as it does ex post facto on a store of contents that have "entered into retention" (i.e., memory) - begins to look a lot like the comparator model which the Husserlian model was expressly called-in to supplant.

Gallagher is aware of this criticism and has insisted that a metarepresentational layering does not necessarily threaten the Husserlian approach, since one may take a "bottom-up" view where "what happens at the cognitive level of self-attribution [...] is straight-forwardly explained as an effect of the lower-order disruptions" (2007b, p. 36). The reply is plausible in isolation. Indeed, it is untendentious that "first-order experience might in fact play a role in the problem" and that "the immediate sense of alterity, may be implicit in first-order experience" (Gallagher 2007b, pp. 39, 45), since it is the element of surprise which goads thought into motion. ${ }^{8}$ Appealing to this feature becomes less attractive, however, when we consider that it requires one to produce a convincing reason why - on the sole basis of a closed set of antecedent conditions - the schizophrenic subject's second-order ${ }^{9}$ interpretation of her mental happenings is compelled to take that precise route, and not another. In other words, thoroughgoing bottom-up approaches must in principle satisfy projectability. There is certainly much complexity involved, as Gallagher observes (2007b, p. 45), but the burden cannot be discharged, at least not with respect to the onset of the psychosis that shall thereafter exploit the momentum of (narrative?) habituation. Yet, as far as I can tell, no convincing evidence has been adduced (bottom-up or top-down) to explain in a concrete way why a higher-order interpretation ends up being what it is in the case of schizophrenics.

Again, Gallagher acknowledges this difficulty, and has recently qualified his earlier support of bottom-up approaches:

The common complaint against these [bottom-up] models is that they never explain why the delusions have the specific thematic contents that they do. [...] In schizophrenia, a person may experience a lack of agency for a particular movement she makes; but why should she come to the delusional explanation that someone else is making her do things, rather than that something is wrong with her own motor control system? There seems to be no resources in these models to answer such questions. (Gallagher 2009a, p. 248)

Despite obvious surface variations, then, it is unclear if and how Gallagher's use of the protentive model marks a tangible advance over existing theories like the one proposed by Frith (1992). Given that the actions perforce unfold in time (i.e., have a more or less natural duration proper to the act performed), there does not seem to be any way to avoid positing sufficiently developed means of juxtaposing what a subject intended to do/think with what was done/thought. Whether this is framed as "metarepresentation" or "comparison," the requirement remains. Moreover, one

\footnotetext{
${ }^{8}$ Note that the alterity of brute encounters with the non-ego is not limited to another person (it encompasses, among other things, ringing telephones).

${ }^{9}$ Gallagher (2007b) often writes as if the mere fact that something is of a second-order propels it to a conscious level amenable to introspection and declarative reporting. While some self-constitution theorists make this same assumption (e.g., Graham and Stephens 1994; Stephens and Graham 2000), it is unwarranted. What makes something "higher" than another is a matter of its relative logical role, not some intrinsic psychologistic property (see Champagne 2009, pp. 558-559).
} 
must take care not to let deliberate inference overtake the more primitive or "covert" (Lethin 2005) pathways which make the situation scientifically and philosophically interesting in the first place. ${ }^{10}$ Frith and Gallagher's models are equally satisfactory on this score. Gallagher's grievance that the standard explanation "makes little phenomenological sense and is in some respects redundant or extraneous" (2000b, p. 230) thus seems to be off the mark. The fact that a subject does not actually perform any overt sort of "comparison" in the ongoing stream of her mental life does not tell against the standard explanatory model developed by Frith and others - nor does it speak in favor of Gallagher's preferred account. ${ }^{11}$

\section{The status of first-person reports}

Given this impasse, the standard phenomenological reflex would be to recommend a return to lived experience. According to Husserl, performing the epoché always makes one a "beginning philosopher" ([1931] 1999, p. 30). When engaging in attentive phenomenological description, one is required to relinquish one's natural tendency to impose on one's phenomenal field a preset order concordant with one's worldview. As Gallagher writes: "Phenomenological approaches are characterized as starting with experience rather than with pre-established theories" (2007b, p. 32).

Prima facie, there is no denying that certain schizophrenic pathologies seem to undermine the traditional construal of the self. "Many patients with schizophrenia describe passivity (delusions of control) experiences in which their thoughts, speech, actions, feelings and drives have been replaced or influenced by those of external agents rather than being produced by their own will" (Blakemore 2000, pp. 187188). Hence, from a strict phenomenological standpoint, cases of "thought insertion" really do seem to violate the solipsist haven which has been the refuge of choice for philosophers wary of skepticism. Of course, the fact that it merely "seems" to one that one is the victim of some outside manipulation provides a ready escape from the quandary - schizophrenia is, after all, regarded as a pathology (and not without good reason). But, this facile dismissal of aberrant reports as "mere appearance"whatever it means - is simply not available to a theorist like Gallagher. Taking up the broad programmatic ambitions laid down by Varela et al. (1991; see Gallagher 2006, p. 134n1), Gallagher's work attempts to combine the methodology of Husserlian phenomenology with the more empirically informed tools and results of cognitive science. As he writes: "Phenomenological psychiatrists and philosophers take the patient's first-person narratives seriously. That is, they regard them as

\footnotetext{
10 There is definitely something to be said for the idea that "participatory sense making" (Gallagher 2009b, pp. 301-304) is a potent contributing factor. Bayne and Pacherie are correct, however, to hold that "[a]gentive self-awareness undoubtedly contains narrative elements, but it is not narrative all the way down" (2007, p. 489). For an account (explicitly related to the work of Bayne and Gallagher) which seeks to explain in a principled way why narrative confabulation could never be all there is to agency, see Champagne (forthcoming).

${ }^{11}$ The considerations of parsimony gestured at in Gallagher's criticism and elsewhere (2004c, p. 8) might have conceivably adjudicated the stalemate between modular and phenomenological elucidations. By such a standard, however, Gallagher's recent suggestion that victims of delusions are "not necessarily mistaken" and might in fact enter into "multiple realities" (2009a, pp. 251, 254-262) would make the former explanatory candidate win hands down.
} 
reflective of the patient's actual experiences" (Gallagher 2007b, pp. 32-33). Given this methodological compact, the possibility of conveniently waving away problematic testimony when it contradicts third-person models is not an option.

So, first-person reports carry quite a bit of weight in the construction of explanatory accounts. In fact, once could say that cognitive science becomes the handmaiden of phenomenology: since we know that this is experienced by a subject as being thus and so, what remains for us is to expand in an informative manner on how and why that is. While it is doubtful Gallagher himself would put things this way, the fact remains that first-person reports are endowed with a veto power of sorts. Indeed, the appearance/reality distinction at the heart of phenomenology makes it basically nonsensical to deny that appearances are indeed as they appear.

Phenomenology is, in a loose sense, the study of how things seem. Yet how things seem is bound up in deep and complex ways with how they are. It is natural to suppose that any knowledge we have of how things are must be based on or mediated by how they seem. But this is not obvious. For seeming presupposes being, and in two ways. On the one hand, seeming is often, if not always, precisely, a seeming to be; to understand a seeming as a seeming is to understand it in relation to an actual or possible being. On the other hand, seemings are beings; whether they turn out to be objects or properties or events or relations, they are in any case not nothing. (Carman 2007, p. 99)

As such, it is hard to see how a cognitive scientist could suddenly step in and proclaim that a subject was not "really" having the experiences she claimed to be having. "Seemings" are epistemologically attractive precisely because they are supposed to halt regresses by being manifestly as they seem. In fact, that was Husserl's central motivation for studying phenomena in their own right, insofar as "we can faithfully describe the 'appearing as appearing' in complete evidence" (Husserl [1913] 1982, sect. 88; see also Thomasson 2003, p. 245).

Gallagher has explicitly contrasted this approach with the "neurophilosophical" program developed by Patricia Churchland. Following Paul Churchland (1981), Patricia Churchland thinks folk theoretic accounts of mental life-however primitive or misguided-indeed merit the label of "theory." As she writes: "Scientific theories [...] are continuous with common sense, they are common sense subjected to critical analysis" (Churchland 2002, p. 111). However, she contends that the deliverances of naive introspection and the folk psychology they have spawned over the centuries can and will eventually be eliminated so as to make way for a more rigorous (i.e., materialist) idiom that is in conformity with what the mature nature sciences are (or will be) telling us about the world. Gallagher opposes such a speculative prognostication and holds that "phenomenology is ineliminable if the project is to pursue a neurobiology of consciousness" (2007a, p. 297). What prompts his confidence in this regard is an argument with a distinctly a priori ring to it. As he puts it: " $[\mathrm{M}] \mathrm{y}$ primary purpose is to keep the following question in the foreground: What are we trying to explain when we try to explain consciousness or intersubjectivity?" (Gallagher 2007a, p. 298). The reasoning here seems to be that an explanatory scheme which departs so completely from first-person experience that it calls into doubt the very existence of such experiences can no longer claim to be elucidating that explanandum, since it has effectively "eliminated" the very object 
it purports to bear upon. It is not that such a theory would do nothing in the way of scientific work - it would clearly have some merit or usefulness. But, the basic argument put forth by Gallagher is that if a long-distance runner makes it to the finish line only to deny that she began at the relevant starting point, she cannot be said to have properly participated in the race-much less claim to have won it.

It is important to underscore that this criticism does not depend on showing that neurophilosophy cannot capture some elusive phenomenal property (say, qualia). ${ }^{12}$ Rather, Gallagher's grievance is that if, on the terms set by Churchland, the theories eventually arrived at purport to be about conscious life, then these cannot do away with consciousness altogether - on pain of now explaining something else (say, a brain). So, the shortcomings of neurophilosophy - at least as Gallagher officially articulates them - are answerable to a logical flaw inscribed in the very terms of the endeavor, not to any positive phenomenological insight that supposedly escapes the natural sciences. ${ }^{13}$ As far as I can see, this criticism of eliminativist programs is well taken. But, it falls short of what is required, insofar as proving Churchland wrong this way does nothing to motivate phenomenology as the replacement or corrective of choice.

This underdetermination notwithstanding, Gallagher recommends that we begin our inquiry with well-conducted phenomenological reports, since this "would provide some essential descriptions that any theory would have to consider" (2007a, p. 302). This is a fairly strong claim: any account of consciousness cannot make do without phenomenological descriptions, since these provide the raw (but purified) materials and set the end-result(s) to be achieved by theorizing. To be sure, Gallagher often speaks of "balancing" the various approaches. He contends, for example, that third-person explanation "makes the phenomenological description sharper, more secure, and intersubjectively verifiable" (2007a, p. 303). But, it is not altogether clear that first-person data could ever be modified in any way. Note that the virtues of "sharpness" and "security" alluded by Gallagher confirm but do not really challenge the results of phenomenological inquiry. Even though Varela (1996, p. 343) originally spoke of a "methodology of reciprocal constraints," Gallagher is surprisingly unequivocal on this score: "If the phenomenology indicates that we are not conscious of $\mathrm{X}$, or that our consciousness is not X-like, but the neurological explanation inserts $\mathrm{X}$ into the picture, so to speak, then the neurological explanation

\footnotetext{
${ }^{12}$ It is worth noting that the very same argument can be marshaled - not just to criticize Churchland's arid ontology — but to undermine Gallagher's onerous suggestion that schizophrenics might live in "multiple realities" (2009a). For if one jettisons the objective gauge in comparison with which delusional states are defined, then, by the same logic, the states in question can no longer be characterized as "delusional."

${ }^{13}$ To be sure, this sort of argument does lend indirect support to those, like Thomas Nagel, who insist that "in discovering sound to be, in reality, a wave phenomenon in air or other media, we leave behind one viewpoint to take up another, and the auditory, human or animal viewpoint that we leave behind remains unreduced" (1974, p. 445). In fact, Gallagher has no qualms about countenancing a more challenging metaphysical outlook, if that is what phenomenological inquiry recommends: "And if what there is includes such things that cannot be reduced to computational processes or the subpersonal activation of neurons, or cannot be quantified, or objectified without loss [...] then to turn away from them and to deny their actuality is in fact being unscientific" (2007a, pp. 311-312; the same claim is made in his 2004b, p. 173). So, although strategic reasons compel Gallagher to avoid endorsing the rich ontology urged by existential phenomenology (see Kelly and Wrathall 1996), he is definitely a fellow traveler.
} 
is not explaining consciousness as it is" (2007a, p. 303). Unless I am missing something, there is no reciprocity here.

Although a number of cognitive scientists believe that first-person reports are indispensable for their research (following Gallagher 2003), it is doubtful most would embrace the uneven marriage of neuroscience and phenomenology just described. Gallagher writes: "If, as neuroscientists, we are looking in the brain to find precisely what schemas of neural activations are doing what, we need to have some kind of precise phenomenological map of what we are conscious of in any particular situation" (2007a, p. 303; see also his 2008, pp. 8-24). In fairness, most neuroscientists already see themselves as drawing the very "map" alluded to by Gallagher and would probably scoff at the idea that their job as experimenters consists in filling out the details left to them by philosophers adept at the art of introspection. ${ }^{14}$ Moreover, one could argue that the scientific community often gauges the significance of a discovery - not by how well it confirms first-person experience-but by how profoundly it calls into doubt our common sense conceptions. Such a challenge is not at all taken to be a telltale sign that one has strayed from the evidence - on the contrary, it is frequently glossed as an indicator of profundity (instance the counter-intuitive "mysteries" of quantum mechanics, which are revered as much for their queerness as for their predictive power). Hence, without dwelling on details pertaining to the sociology of actual scientific practice, it might be said that Gallagher's (1997) picture of a "mutual enlightenment" between the cognitive sciences and phenomenology is predicated on a questionable view of how disciplinary identities are constituted and institutionally reproduced.

\section{Coming full circle}

Most phenomenologists striving for reconciliation with the natural sciences recognize that compromises and adjustments are required on both sides. Gallagher and Varela acknowledge that " $[\mathrm{t}]$ here are many thinkers well versed in the Husserlian tradition who are not willing to consider the validity of a naturalistic science of mind" (2001, p. 17). ${ }^{15}$ Contemporary advocates of a rapprochement are indeed correct to remark that "[p]henomenology will have to overcome its phobic tendencies and enter into a critical dialogue with analytical philosophy, cognitive science, and the behavioral sciences" (Parnas and Zahavi 2000, p. 12). Yet, notice how the reluctance alluded to is characterized respectively as a "lack of willingness" and "phobia" - and not any intrinsic methodological or metaphysical incompatibility. Alan Murray-a vocal proponent of the naturalization of phenomenology — states for example that "it is not

\footnotetext{
${ }^{14}$ Parnas is bolder still: "Only continental phenomenology, despite its internal divisions and terminological difficulties, offers a well-developed methodology for studying first-person experience" (2000, p. 119).

${ }^{15}$ Even though he also championed a bridging of disciplines (see Dreyfus and Hall 1982), Hubert Dreyfus' better-known work (e.g., his 1979) remains a good example of how not to construe the relation between phenomenology and the cognitive sciences, according to Gallagher: "[W]hen phenomenologists have seriously engaged the project of the cognitive sciences, rather than pursuing a positive rapprochement with this project, they have been satisfied in drawing critical lines that identify its limitations" (Gallagher and Varela 2001, p. 17).
} 
phenomenology as such which is 'irreconcilable with the contemporary sciences of cognition,' but the attitudes of phenomenologists" (2002, p. 45).

Although there is certainly a grain of truth in the various accusations of "bad faith," it is unclear how a concerted shift in attitude alone could resolve the tangible tensions that exist between first-person and third-person approaches-tensions which, it should be remembered, have been prominent in the West's intellectual history far before anyone ever thought of articulating inquiries like "phenomenology" and "cognitive science." Indeed, as was seen in the previous section, the problems nested in Gallagher's hybrid methodology do not stem merely from a phobic Puritanism on the part of the various theorists involved. Even with an abundance of good will and ingenuity, the attempt to reconcile first-person phenomenology and third-person science remains riddled with difficulties, both substantive and methodological. What impact does this have, then, on the claim that the phenomenon of thought insertion might pose a serious challenge to the Cartesian immunity principle?

The denouement of Gallagher's multifaceted foray into that momentous philosophic possibility is not at all what one would expect. Given the amount of effort spent on meticulously analyzing existing accounts of schizophrenia, it is somewhat shocking that, when all is said and done, Gallagher openly concedes that the attempt to falsify the Cartesian conception of the self by means of clinical psychology and phenomenology ultimately could never have succeeded. He says as much at the close of a lengthy study:

There is good reason to believe that the immunity principle remains intact even in cases of inserted thoughts. When the schizophrenic reports that certain thoughts are not his thoughts, that someone else is generating these thoughts, he is also indicating that these thoughts are being manifested, not "over there" in someone else's head, but within his own stream of consciousness, a stream of consciousness for which he claims ownership. In other words, his complaint with regard to inserted thoughts is not that he is suddenly telepathic, but that someone else has invaded his own mind. [...] He is experiencing thoughts that seem to be generated by others. His phenomenology is this: he has a sense of ownership for the stream of consciousness which is impossible to misidentify (and is, in fact, in no need of identification, since it is his own), but into which are inserted thoughts for which he has no sense of agency. His judgement that it is he who is being subjected to these thoughts is immune to error through misidentification, even if he is completely wrong about who is causing his thoughts. In the latter case, with respect to agency, he is in a position to make only statements in which he uses the first person pronoun as object-and in such cases the immunity principle is not at stake, and therefore cannot be violated. (Gallagher 2000b, pp. 230-231)

There is an important sense in which this statement could have been made prior to and independently of any empirical and/or introspective data. Gallagher is forced to concede that the schizophrenic subject "has a sense of ownership for the stream of consciousness which is impossible to misidentify" (2000b, p. 231; emphasis added). This impossibility is underwritten by (conveniently undefined) a priori constraints. Hence, whereas Campbell holds that "[i]t is easy but mistaken to represent the patient as saying something which is straightforwardly self-contradictory” (1999b, p. 620), 
that characterization cannot so easily be dismissed. For while "it is plausible to think that thoughts are not identified uniquely on the basis of their propositional content, but also on the basis of the attitude that the subject has towards that content" (Bortolotti and Broome 2009, p. 221), not all reasons given by a person are good reasonswhatever the degree of endorsement (or lack thereof). In the final analysis, then, logical considerations play a decisive role in determining how best to characterize the situation. In fact, Gallagher's statement that the schizophrenic's "judgement that it is he who is being subjected to these thoughts is immune to error through misidentification, even if he is completely wrong about who is causing his thoughts" (2000b, p. 231) is an almost verbatim summation of the famous argument deployed by Descartes in the Meditations ([1642] 1984).

Hence, far from calling into question the Cartesian account of the self's immunity, I submit that the investigations into thought insertion carried out by Gallagher provide a further confirmation of that philosophic viewpoint's overall rectitude by showing that even those afflicted patients whose sense of agency is radically disconnected are minimally compelled to take those dislocated episodes as their own. ${ }^{16}$ Going back to the handy characterization introduced earlier, we can say that in the very act of reporting a given experience, a patient must (logically if not verbally) tag an infallible "I think that..." before every content-even when what falls under that functor yields "I think that [someone else thinks that]..." In other words, Cartesian "thought insertion" trumps schizophrenic thought insertion.

This does not mean that schizophrenics plagued by thought insertion could ever chase away their affliction by rehearsing canonical anti-skeptical arguments. ${ }^{17}$ True, Descartes' narrator briefly contemplates the possibility that he may be mad ([1642] 1984, p. 13). But, "[t]he task [Descartes] sets for himself in the Meditations is not to discover how a madman can find a foundation for the sciences" (Frankfurt 1970, p. 38). Likewise, I proffer no remedy; my point has been philosophical, not clinical. Whatever one makes of that status, it has the merit of responding to its rival in kind, insofar as theorists who toy with the idea that the immunity principle may not be impervious to counterexamples do not intend by this that healthy individuals might also not know "who" is thinking their thoughts (although insinuations of such a slide arguably drive much of the interest).

\footnotetext{
${ }^{16}$ A widespread distinction proposed by Campbell (1999a; 2002) and taken up by Gallagher might lead some to reply that the immunity to error pertains only to "sense of agency," not "sense of ownership." Bortolotti and Broome (2009) have recently adduced reasons for dismissing this gloss, and their criticisms definitely merit attention in their own right (although one might question whether it is truly an advance to swap the spatial analogy of ownership for a "legal" one). But, the present context does not even require that one take a stand on the ownership/agency distinction. Since the starting claim (enunciated by Campbell and entertained by Gallagher) pertained to immunity to error through misidentification as such, it suffices to show that ownership falls under that Cartesian thesis to show that the claim of falsification is itself falsified.

${ }^{17}$ Note that it is not the "Cogito ergo sum" - the idea that one could somehow deduce the existence of reality from the prior certainty of one's consciousness - that still stands. Rather, it is the (more limited) present-tense immunity to error through misidentification relative to the first-person pronoun that still stands. Both tenets admittedly originate in Descartes (Shoemaker 1968, p. 559); but nothing I have said in this paper supports grand speculations about substance dualism, wide-scale deception, Godly benevolence, pineal glands, mechanistic animals, and the like.
} 


\section{Conclusion}

Sweeping generalizations are handicapped by their very scope, as they stand open to defeat by a single contrary piece of evidence. With this in mind, a challenging naturalistic claim has been made: certain case studies in psychiatry suggest that the border which separates self from other is not as impermeable as philosophers have usually taken it to be, since "[a] patient who supposes that thoughts have been inserted into his mind by someone else is right about which thoughts they are, but wrong about whose thoughts they are" (Campbell 1999b, pp. 609-610; emphasis added). In such instances, we have an apparent transgression of those concentric rings of selfhood famously described by William James ([1890] 2007, pp. 291-305). Divorcing a limb is disturbing enough; but to the extent this sort of pathological breakdown begins to imperil the privileged epicenter where the ego is said to lie, the predicament potentially becomes philosophically troubling as well. I have followed Shaun Gallagher's sustained engagement with this remarkable contention. After surveying the phenomenological effects of visuo-motor coordination, looking at competing proposals about how best to frame the experience of temporal anticipation, and addressing the contested status of first-person reports in cognitive scientific inquiry, the end-result of my endeavor is surprisingly plain: the claim that the Cartesian immunity to error principle has been falsified by the phenomenon of schizophrenic thought insertion simply does not bear out.

I must confess that coming to Descartes' defense-even indirectly, by way of this double-negation - is an uncomfortable role for me to play. Still, the immunity principle is big game, and having carefully reviewed the data and its various theoretical interpretations, I see no convincing reason to think pathology could ever knock it off. When Gallagher concedes that "There is good reason to believe that the immunity principle remains intact even in cases of inserted thoughts" (2000b, p. 230), the "good reason" in question comes from neither phenomenology nor the cognitive sciences. At the risk of curbing the ambitions of an otherwise legitimate research program, this realization's armchair pedigree needs to be made explicit and given its due. To be sure, Descartes' success on this particular day does not gainsay Gallagher's impressive multidisciplinary fact-gathering. But, the unsubstantiated intimation of a naturalist counterexample to the traditional boundary between self and other makes Gallagher's claim to "productivity" sound rather hollow.

So, what does this say about the attempt to conjoin first-person and thirdperson approaches to address philosophical debates-about the often fractious negotiation between results of experimental science, insights arrived at by phenomenological description, and conclusions supported by impersonal logic? Murray observes that philosophers "are unlikely to sacrifice beliefs which are, after all, extremely flattering and which, for a long time now, have formed such an important part of their sense of identity" (2002, p. 45). That observation is no doubt true (and if so, it applies not just to philosophy). Still, whatever misgivings one may have about purely rational argumentation, the fact that Gallagher has returned from a lengthy exploration without fruit might lead one to reconsider in a more charitable light Ryle's statement that "One will never say that so and so is a better philosopher than so and so because so and so knows facts of which the other is ignorant." 
Acknowledgments The author would like to thank David Jopling, Kristin Andrews, Craig Roxborough, Joshua Mugg, Michael Braund, and anonymous reviewers from this journal for helpful feedback (the usual caveats apply). The continued support of York University's Department of Philosophy is also gratefully acknowledged.

\section{References}

Baker, L. R. (2000). Persons and bodies. Cambridge: Cambridge University Press.

Bayne, T. J., \& Levy, N. (2006). The feeling of doing: Deconstructing the phenomenology of agency. In N. Sebanz \& W. Prinz (Eds.), Disorders of volition (pp. 49-68). Cambridge: MIT.

Bayne, T. J., \& Pacherie, E. (2007). Narrators and comparators: The architecture of agentive selfawareness. Synthese, 159, 475-491.

Blakemore, S.-J. (2000). Monitoring the self in schizophrenia: The role of internal models. In D. Zahavi (Ed.), Exploring the self: Philosophical and psychopathological perspectives on self-experience (pp. 185-202). Amsterdam: John Benjamins.

Bortolotti, L., \& Broome, M. R. (2009). A role for ownership and authorship in the analysis of thought insertion. Phenomenology and the Cognitive Sciences, 8, 205-224.

Campbell, J. (1999a). Immunity to error through misidentification and the meaning of a referring term. Philosophical Topics, 26, 89-104.

Campbell, J. (1999b). Schizophrenia, the space of reasons, and thinking as a motor process. Monist, 82, 609-625.

Campbell, J. (2002). The ownership of thoughts. Philosophy, Psychiatry and Psychology, 9, 35-39.

Carman, T. (2007). Dennett on seeming. Phenomenology and the Cognitive Sciences, 6, 99-106.

Champagne, M. (2009). Some semiotic constraints on metarepresentational accounts of consciousness. In J. N. Deely \& L. G. Sbrocchi (Eds.), Semiotics 2008: Specialization, semiosis, semiotics (pp. 557564). New York: Legas.

Champagne, M. (2011). Schopenhauer, semiosis, and the feasibility of a "phenomenology of agency." Cognitive Semiotics (in press).

Churchland, P. M. (1981). Eliminative materialism and the propositional attitudes. Journal of Philosophy, 78, 67-90.

Churchland, P. S. (2002). Brain-wise: Studies in neurophilosophy. Cambridge: MIT.

Cole, J., Sacks, O., \& Waterman, I. (2000). On the immunity principle: A view from a robot. Trends in Cognitive Sciences, 4, 167.

Descartes, R. ([1642] 1984). Meditations on first philosophy. The Philosophical Writings of Descartes, vol. 2 (pp. 12-62). Trans. by J. Cottingham, R. Stoothoff \& D. Murdoch. Cambridge, UK: Cambridge University Press

Dreyfus, H. L. (1979). What computers can't do: The limits of artificial intelligence. New York: Harper \& Row.

Dreyfus, H. L., \& Hall, H. (Eds.). (1982). Husserl, intentionality, and cognitive science. Cambridge: MIT.

Farrer, C., \& Frith, C. D. (2002). Experiencing oneself vs. another person as being the cause of an action: The neural correlates of the experience of agency. Neuroimage, 15, 596-603.

Feinberg, I. (1978). Efference copy and corollary discharge: Implications for thinking and its disorders. Schizophrenia Bulletin, 4, 636-640.

Franck, N., Farrer, C., Georgieff, N., Marie-Cardine, M., Daléry, J., d'Amato, T., et al. (2001). Defective recognition of one's own actions in patients with schizophrenia. The American Journal of Psychiatry, 158, 454-459.

Frankfurt, H. G. (1970). Demons, dreamers, and madmen: The defense of reason in Descartes's meditations. New York: Bobbs-Merrill.

Frith, C. D. (1992). The cognitive neuropsychology of schizophrenia. Hillsdale: Lawrence Erlbaum.

Gallagher, S. (1997). Mutual enlightenment: Recent phenomenology in cognitive science. Journal of Consciousness Studies, 4, 195-214.

Gallagher, S. (1998). The inordinance of time. Evanston: Northwestern University Press.

Gallagher, S. (2000a). Philosophical conceptions of the self: Implications for cognitive science. Trends in Cognitive Science, 4, 14-21.

Gallagher, S. (2000b). Self-reference and schizophrenia: A cognitive model of immunity to error through misidentification. In D. Zahavi (Ed.), Exploring the self: Philosophical and psychopathological perspectives on self-experience (pp. 203-239). Amsterdam: John Benjamins.

Gallagher, S. (2003). Phenomenology and experimental design: Toward a phenomenologically enlightened experimental science. Journal of Consciousness Studies, 10, 85-99. 
Gallagher, S. (2004a). Agency, ownership, and alien control in schizophrenia. In D. Zahavi, T. Grünbaum, \& J. Parnas (Eds.), Interdisciplinary perspectives on self-consciousness (pp. 89-104). Amsterdam: John Benjamins.

Gallagher, S. (2004b). Hermeneutics and the cognitive sciences. Journal of Consciousness Studies, 11, 162-174.

Gallagher, S. (2004c). Neurocognitive models of schizophrenia: A neurophenomenological critique. Psychopathology, 37, 8-19.

Gallagher, S. (2006). How the body shapes the mind. Oxford: Clarendon.

Gallagher, S. (2007a). Neurophilosophy and neurophenomenology. In L. Embree \& T. Nenon (Eds.), Phenomenology 2005: Vol. 5, selected essays from North America (pp. 293-316). Bucharest: Zeta.

Gallagher, S. (2007b). Sense of agency and higher-order cognition: Levels of explanation for schizophrenia. Cognitive Semiotics, 0, 32-48.

Gallagher, S. (2008). Brainstorming. Exeter: Imprint Academic.

Gallagher, S. (2009a). Delusional realities. In M. R. Broome \& L. Bortolotti (Eds.), Psychiatry as cognitive neuroscience: Philosophical perspectives (pp. 245-266). Oxford: Oxford University Press.

Gallagher, S. (2009b). Two problems of intersubjectivity. Journal of Consciousness Studies, 16, 289-308.

Gallagher, S., \& Brøsted Sørensen, J. (2006). Experimenting with phenomenology. Consciousness and Cognition, 15, 119-134.

Gallagher, S., \& Varela, F. J. (2001). Redrawing the map and resetting the time: Phenomenology and the cognitive sciences. In S. Crowell, L. Embree \& S. J. Julian (Eds.), The reach of reflection: The future of phenomenology (pp. 17-45). Center for Advanced Research in Phenomenology

Graham, G., \& Stephens, G. L. (1994). Mind and mine. In G. Graham \& G. L. Stephens (Eds.), Philosophical psychopathology (pp. 91-109). Cambridge: MIT.

Haggard, P., \& Clark, S. (2003). Intentional action: Conscious experience and neural prediction. Consciousness and Cognition, 12, 695-707.

Husserl, E. ([1893-1917] 1991). On the phenomenology of the consciousness of internal time. Trans. by J. Brough. Collected Works, 4. Dordrecht: Kluwer.

Husserl, E. ([1913] 1982). Ideas pertaining to a pure phenomenology and to a phenomenological philosophy, first book. Trans. by F. Kersten. Collected Works, 2. The Hague: Martinus Nijhoff.

Husserl, E. ([1931] 1999). Cartesian Meditations. Trans. by D. Cairns. Dordrecht: Kluwer.

James, W. ([1890] 2007). The Principles of Psychology, vol. 1. New York: Cosimo.

Johnson, M. K. (1988). Discriminating the origin of information. In T. F. Oltmanns \& B. A. Maher (Eds.), Delusional beliefs: Interdisciplinary perspectives (pp. 34-65). New York: Wiley.

Kelly, S. D., \& Wrathall, M. (1996). Existential phenomenology and cognitive science. Electronic Journal of Analytic Philosophy, 4.

Lethin, A. (2005). Covert agency with proprioceptive feedback. Journal of Consciousness Studies, 2, $96-114$.

Lethin, A. (2008). Anticipating sensitizes the body. Phenomenology and the Cognitive Sciences, 7, 279-300.

Lysaker, P. H., Johannesen, J. K., \& Lysaker, J. T. (2005). Schizophrenia and the experience of intersubjectivity as threat. Phenomenology and the Cognitive Sciences, 4, 335-352.

Merleau-Ponty, M. ([1945] 1974). Phenomenology of perception. Trans. by C. Smith \& F. Williams. London: Routledge \& Kegan Paul.

Merleau-Ponty, M., \& Ryle G. ([1960] 1992). Phenomenology and analytic philosophy. In H. J. Silverman \& J. Barry (Eds.), Texts and Dialogues (pp. 59-72). Atlantic Highlands, NJ, \& London: Humanities Press.

Murray, A. (2002). Philosophy and the 'anteriority complex'. Phenomenology and the Cognitive Sciences, 1, $27-47$.

Nagel, T. (1974). What is it like to be a bat? Philosophical Review, 83, 435-450.

Nielsen, T. I. (1963). Volition: A new experimental approach. Scandinavian Journal of Psychology, 4, 225-230.

Parnas, J. (2000). The self and intentionality in the pre-psychotic stages of schizophrenia. In D. Zahavi (Ed.), Exploring the self: Philosophical and psychopathological perspectives on self-experience (pp. 115-147). Amsterdam: John Benjamins.

Parnas, J., \& Zahavi, D. (2000). The link: Philosophy-psychopathology-phenomenology. In D. Zahavi (Ed.), Exploring the self: Philosophical and psychopathological perspectives on self-experience (pp. 1-16). Amsterdam: John Benjamins.

Schwartz, M. A., Wiggins, O. P., Naudin, J., \& Spitzer, M. (2005). Rebuilding reality: A phenomenology of aspects of chronic schizophrenia. Phenomenology and the Cognitive Sciences, 4, 91-115.

Shoemaker, S. S. (1968). Self-reference and self-awareness. Journal of Philosophy, 65, 555-567.

Slatman, J. (2009). A strange hand: On self-recognition and recognition of another. Phenomenology and the Cognitive Sciences, 8, 321-342.

Stephens, G. L., \& Graham, G. (2000). When self-consciousness breaks: Alien voices and inserted thoughts. Cambridge: MIT. 
Thomasson, A. L. (2003). Introspection and phenomenological method. Phenomenology and the Cognitive Sciences, 2, 239-254.

Varela, F. J. (1996). Neurophenomenology: A methodological remedy for the hard problem. Journal of Consciousness Studies, 3, 330-349.

Varela, F. J., Thompson, E., \& Rosch, E. (1991). The embodied mind: Cognitive science and human experience. Harvard: MIT.

Waldenfels, B. (2004). Bodily experience between selfhood and otherness. Phenomenology and the Cognitive Sciences, 3, 235-248.

Wittgenstein, L. (1958). The blue and brown books. Oxford: Blackwell. 